\title{
The Role of Individual Absorptive Capacity, Subjective-Wellbeing and Cultural Fit in Predicting International Student's Academic Achievement and Novelty in China
}

\author{
Emmanuel Tetteh Teye ${ }^{1}$, Alexander Narh Tetteh ${ }^{1}$, Abraham Teye $^{4}$, Seth Yeboah Ntim ${ }^{3}$, Beatrice Ayerakwa Abosi ${ }^{1}$, \\ Olayemi Hafeez Rufai ${ }^{1} \&$ Qian $\mathrm{He}^{2}$ \\ ${ }^{1}$ School of Public Affairs, University of Science and Technology of China \\ ${ }^{2}$ School of Management, University of Science and Technology of China \\ ${ }^{3}$ Zhejiang Normal University China \\ ${ }^{4}$ University of Education Winneba Ghana \\ Correspondence: Emmanuel Tetteh Teye, School of Public Affairs, University of Science and Technology of China, \\ China.E-mail: kelvin4u09@gmail.com/ emmateye@mail.ustc.edu.cn
}

Received: November 2, 2018

Accepted: November 29, 2018

Online Published: December 4, 2018

doi:10.5430/ijhe.v7n6p78

URL: https://doi.org/10.5430/ijhe.v7n6p78

\begin{abstract}
This study investigated the role of cognitive-(absorptive capacity), psychological-(subjective-wellbeing) and cultural-fit-factors as predictors of academic achievement-novelty in a Chinese-C9-league-University. We addressed the question of what drive student's achievement of high graduations requirements and innovativeness in their Host-University; focusing mainly on whether interactionistic-nature-(fit-capabilities) are better mechanisms. The quantitative approach was adopted; collect 234 valid data via survey questionnaire (Note 1), and conduct analysis via structural equation modeling technique. We found that individual-absorptive-capacity has significant effect on supervisor-fit, but a non-significant effect on university-fit dimensions of cultural-fit. Subjective-wellbeing significantly affects both dimensions of cultural-fit. The findings further show how supervisor-fit and university-fit indirectly mediate the (absorptive-capacity, subjective-wellbeing)-achievement-novelty relationship. We highlight the importance of cultural-diversity-awareness; considering supervisor-institutional-fit-factors in research-mentorship-development to support international-students 'induction for research productivity in educational-settings.
\end{abstract}

Keywords: individual-absorptive-capacity, subjective-wellbeing, cultural-fit, academic-achievement-novelty, dynamic-learning-environment, international-students, higher-education

\section{Introduction}

In this period of globalization and information technology, multi-cultural-like education is seen as a door to every human activity. Higher education institutions are currently faced with historically unprecedented circumstance in the midst of more than 4.1 million international students enrolled worldwide (UNESCO, 2017). According to Ivor Crewe, president of Universities in UK, "reliance on international students has become "inevitable" and these students are no longer an "optional extra" for universities (Taylor, 2005). Asian countries like China dominate the suppliers of international students to long-established receivers mainly USA, UK, Australia, Canada and New Zealand. Given the prediction that universal transit of students will increase from 2.1 million in 2003 to roughly 5.8 million by 2020, (Asteris 2006) China as part of her "Soft power strategy" has laid significant emphasis on attracting international enrollments and enriching higher education in recent years. China has piercingly expressed its aspiration to compete with other traditional and new receiving countries in terms of international enrollment by setting a target to attract 500,000 students by 2020 . However, improving international students' study experience is a strategic issue faced by most universities given the growing competition between each other (Böhmet al 2004). The great importance of international students to receiving universities cannot be over-emphasized. Apart from financial contribution to host-institutions' progress, international students' distinctive demand from home students for various programmesfor instance Sciences, Technology, Mathematics and Engineering probes receiving institutions to maintain a diverse array of disciplines. It is worth noting that the, responsibility for serving international students 
educational needs is at the cross-road of balance while students are faced with the tandem need to prove excellence (Ploner, 2018), in their academic achievement. Hence, in every aspect of student's life and its surrounding social activities, there is need for cognitive capacity, psychological well-being and environmental-fit abilities to achieve success. This study aims to identify the key antecedents, especially those cognitive, psycho-emotional and environment-fit related ones, which influence students' academic achievement and novelty at the postgraduate level, considering the predominant proportion of diverse students engaged in academic research in China. The results of this study highlights the importance of increasing cultural diversity awareness in higher education settings to better support international students' learning experience and gain competitiveness in the international education market. Specifically, linking absorptive capacity, subjective well-being and cultural-fit effects to the study of postgraduate student's academic performance and novelty advances a promising understanding in the field of higher education and research productivity.

In the next sections, we present literature review, proposed conceptual framework and hypotheses. Following this, we present methodology and the empirical findings. We conclude with discussion and suggestions for future research.

\section{Literature review}

\subsection{Connection among Predictor Factors of Student's Academic Achievement in the Present Study}

Individual absorptive capacity, subjective-wellbeing and environment-fit capability are very crucial for individuals to attain academic success in today's highly challenging educational environment (Luigi, Maxim, \&Concetto. 2017; Yong, Seong and Kun, 2014; Rafiza and Yee Chen See, 2010). March \&Simion, (1958), have argued that innovation which happens in many organizations can be attributed to the organization's ability to acquire external resources than inventing it internally. Building on this notion, Cohen \&Levinthal, (1990) found that the ability of institutions or individuals to access new knowledge or information and use it, plays an important role for the overall innovativeness and performance. The authors argue that the ability to apply the new knowledge will be as a result of prior related knowledge. Cohen \&Levinthal then named these abilities "absorptive capacity". Absorptive capacity is the ability to recognize the value of external knowledge for personal development (Cohen and Levinthal, 1990; Francesca and Gary, 2014). In this process of innovation, imitation is important which can be a capacity that is acquired from external environment. Although, Cohen and Levinthal view of absorptive capacity is not directly in-line of academic settings but organizational settings, its value cannot be under-mined at the individual level in all spheres of life. Previous studies found that absorptive capacity is positively correlated to innovation both at the organizational and human levels (Huang et. al., 2015).

Since human beings are tied to their emotions (Yong, Seong and Kun, 2014), they are swayed by their subjective-wellbeing. Subjective-wellbeing is the self-internal happiness derived by individuals that motivated them to accomplish a specific task (Wang and Yang, 2017; Diener et al., 2005). Currently, subjective well-being is considered an important psychological factor as its imperative has been explored in social and behavioral studies by some researchers (Seligman \&Csikszentmihalyi, 2000; Honkaniemi et al., 2015). Whereas Robertson \& Cooper (2010) posit that subjective well-being can be linked to a person's engagement, recent research on the subject also indicate that, a sustainable sense of well-being plays a major role in the meaning of one's life, as it can increase organizational commitment, adjusting to new environments, accepting responsibility, creativity and ability to come out with new ideas and reduce labor turnover (Chumg et al., 2016; Hashim and Tan (2015; Cohn et al., 2009). The understanding that students achieve academic performance based on either adaptive or maladaptive patterns which influence cognitive performance is critical. Dweck (1986) and Ames (1992) argued that student performance is determined by their ability to show positive attitude towards learning. The extant literature has paid adequate attention to absorptive capacity and subjective-well-being to academic accomplishment propensity. However, little is known about exploring the effect of cultural-fit on the novelty and academic performance of international students. This study put into consideration person-environment-fit phenomenon(Aichia Chuang et al 2016)representing cultural-fit. Culture has been described as a system where there are behavior norms among a common group of people (Patterson, 2014, small, Harding \& Lamont, 2010, Dimaggio, 1997). Studies on how individuals fit into social groups has gain massive attention across major disciplines in social sciences of which education is one of the key focus (Sanaz, 2017). Cultural-fit is the likelihood that an individual will be able to conform and adapt to the core values and collective behavior that make up an organization. Studies have argued that, lack of cultural-fit may bring about dissatisfaction, poor productivity, excessive absence, and turnover. In the organizational field, studies have shown that employees, who are a good cultural-fit, work excellently within the environment of the company they belong. 


\subsection{Conceptual Framework and Hypothesis}

Based on the aforementioned linkage above, the present study focus on predicting international graduate students' perception by empirically addressing the following questions;

1. Does absorptive capacity and subjective well-being serve as drivers for student's attainment of graduate requirements and novelty in Host University?

2. Do cultural fit (supervisor-fit and institution-fit) serve as better mechanism?

\subsubsection{Individual-Absorptive-Capacity}

Cohen and Levinthal, 1990 drawn from March \&Simion, 1958, explained that the main idea of absorptive capacity was the need to assimilate and use new knowledge using prior related knowledge. Absorptive capacity can then be seen as the individuals' ability to ascertain new knowledge or information, understand how it works and use it for a gain (Cohen and Levinthal, 1990). Studies have found absorptive capacity brings about high productivity and innovation, making it one of the key drivers of innovation. (Lau and Lo, 2015; Huang et. al., 2015; Szulanski,1996). It is important to note that the cognitive and behavioral dimensions of people towards a group they belong, is vital and highly correlated to individuals achievement since it help them to fit into the culture of the group (Sanaz et. al., 2017). Since absorptive capacity has the tendency to acknowledge and value new knowledge, individuals with higher absorptive capacity are better to applying knowledge for gain. (Deng et. al., 2008; Cegarra Navarro et. al., 2014), in-like manner, individuals with higher absorptive capacity will have a higher mental representation which can easily drive their beliefs and values to fit into a particular institutional culture (Sanaz et. al. 2017). From these backgrounds, one can argue that, the ability of an individual to understand and fit into the culture of his/her institution could have a positive impact on his/her achievement in that institution.

\subsubsection{Subjective-Wellbeing}

According to Burns and Machin, (2009), subjective well-being is related to the awareness of pleasure, satisfaction, and happiness. As an important psychological factor, numerous studies have explored the role of subjective-wellbeing on individual's behavior and engagements. (Diener et al.2005; Seligman and Csikszentmihalyi, 2000; Honkaniemi et al., 2015; Robertson and Cooper 2010; Chumg et al., 2016; Spector, 1997; Hashim and Tan 2015). Other scholars postulates that one with positive subjective-wellbeing (positive emotions) can help the individual to remember information, increase academic and life related satisfaction and boost creative problem solving (Koveshnikov et al., 2014; Cohn et al., 2009; Ryan and Deci, 2001). Recently Henttonen et al. (2016) have concluded that, an individual with positive knowledge sharing ability would be positively linked with knowledge sharing behavior. Thus an individual with positive emotions, such as subjective well-being, will be likely sharing tacit and explicit knowledge with respect to student-institutional-fit and student's motivation to attained academic requirements.

\subsubsection{Cultural-Fit}

The bout between individuals and the environment has long been of interest to academicians and organizational psychologists (Kristof-Brown, Zimmerman, \& Johnson, 2005; Grobler et. al 2018), as well employers, superiors, job seekers, student applicants and incumbent workers in all spheres of human engagements (Kristof-Brown, 2000). Recent advances in fit theory (Kristof-Brown \&Guay, 2011) have served as the basis for some researchers to further considerthe concept of person-environment-fit as an important goodwill in the interactionist theory of behavior; upon the supposition that certain environments match to each individual, mostly corresponding the characteristics of the individual's traits, and that this association, sequentially, results in higher performance, higher satisfaction and innovativeness across all cultures (Pervin 1968). According to Kristof-Brown \&Guay, (2011) four dimensions of person-environment fit exist; person-job fit, person-organization fit, person-group fit and person-supervisor fit. These dimensions have been given attention by scholars in the literature on work attitudes, turnover, performance, innovation, job search, and managerial selection decisions, and student's success in unfamiliar environments (Kristof-Brown et al., 2005; Grobler et. al 2018). Studies on educational field, establish that there is positive correlation between school culture and students' achievement (Al Fara, Samia, 2012; Elbot\& Fulton, 2008; Carter, 2011). In the present study we have paid attention to student-university-fit and student-supervisor-fit dimensions of person environment-fit and labeled as cultural-fit; an important predictor of international student's academic success and innovative behavior. 


\subsubsection{Environmental-Dynamism}

The environment is anything outside an individual or institution that may affect their expected performance. Researchers have acknowledged that external environmental factors can moderate cognitive and market orientations, innovation strategy, and investments effect on performance both at the individual and organizational levels (Allred and Swan 2005; Freel 2005). Environmental dynamism has been explained to broadly include; continuous change in technology, market demand, competition, uncertainty, risk, challenges, unpredictable change. With regard to the present study focus, we describe specifically university dynamic learning atmosphere(frequency of visiting professors from abroad, innovative climate, university competitiveness in and outside china); and study abroad challenges within our sample.

\subsubsection{Academic-Achievement-Novelty of International-Students}

Salisbury, (2011) posit that, study abroad and cultural exchange programs are mainly designed to expose students to new experiences and to develop their cultural awareness, sensitivity, and communication skills. Decades now, academic performance of students in higher education has been the subject of intensive research (Head, 1990). A series of performance predictors have been developed and categorized into academic, psychosocial, cognitive and demographic categories (McKenzie \& Schweitzer, 2001). Some researchers have also focus on course quality assurance, graduation rates, dissertation requirements, novelty, time to degree, retention, publications, and GPA in relation international students dynamic-learning-environments (Ingraham \& Peterson, 2004; Metzger, 2006; Yorke, 1991).

With regard to academic factors, some studies have shown the dominant role learning skills and habits play in predicting students' academic performance (McKenzie \&Schweitze, 2001; McKenzie, Gow\& Schweitzer, 2004; Abbott- Chapman, Hughes \&Wyld, 1992). In the case of psychosocial predictors; social adaptation into the university/ supervisor system, financial situation, motivation, social and emotional support and subjective-wellbeing been identified to influence students' success and novelty (Terenzini and Pascarella 1978; Lecompteet al 1983; Pokay and Blumenfeld 1990; Gerdes and Mallinckrodt 1994).

The cognitive predictors have been explained by authors as self-efficacy, attribution tendency style, and absorptive capacity. (Pajares 1996; Lecompteet al 1983; McKenzie \& Schweitzer 2001; Yee et al 2004; Cohen \&Levinthal, 1990). Self-efficacy means students' self beliefs about their capabilities to initiate and successfully perform specified tasks at designated levels. An individual's attribution refers to his/her general tendency to generate similar causal explanations across events. An individual absorptive capacity can be seen as the individuals' ability to ascertain new knowledge or information, understand how it works and use it for a gain.

Amongst the various predictors above, there is probability for some interactions between each other, and therefore the consequence of one factor on example; the psychosocial predictors might obliquely reflect and or be complimented through others to predict international student's academic success.

According to MacKeogh (2006), the strongest support that students receive comes from their supervisor/ university resources. Todd et al. (2004) in a study undertaken with final year social science undergraduates grouped four roles assigned to supervisors; to provide academic direction (selecting research methodologies, structuring the thesis), to motivate (setting responsibilities and deadlines), to have (and communicate) academic expertise in the area of the dissertation and to help them write the dissertation. University specific values, climate, competitiveness, cultural diversity and learning resources are crucial for international student's adaptations and success (Airini 2012; Bennett 2003; Mayeda, Keil, Dutton, \& 'Ofamo'oni 2014). Especially in the case of China, in addition to language shock, there are many other culture-specific factors associated with academic behavior and achievement such as social culture shock, academic culture shock (Gilbert, 2000; Robertson et al, 2000; Hau\&Salili, 1996; Smith \& Smith, 1999; Webb \& Read, 2000). Recent study by Li et.al (2010) examined perceived value of study, learning preference, leaning effort, familiarity of learning environment, social communication effects on international student's achievement in the Chinese higher education context. As the present study focus on the direct and indirect effects of some key factors, it is not necessary to include all of the above mentioned aspects into the hypothesized model and analysis. 


\subsection{Proposed Model}

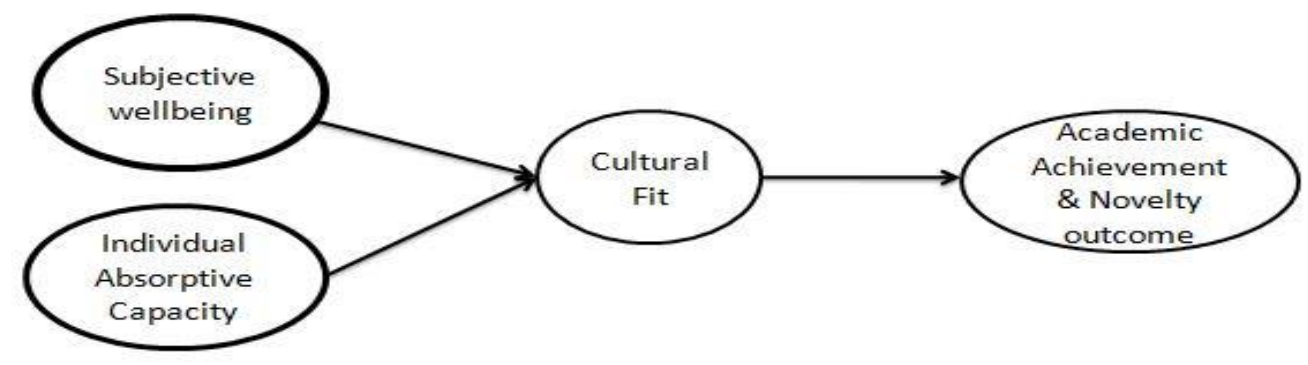

- Fig 1 Antecedent model of academic achievement and novelty behavior

Source: Authors, 2018

\subsection{Hypothesis}

Fig1.illustrates the research model composing of four main constructs: The model predicts that graduate student's academic achievements and research novelty is influenced directly and indirectly by individual absorptive capacity and subjective well-being to study while cultural-fit is regarded as a mediator. The study also examined the descriptive situation of environmental dynamism and challenges related to study abroad. See figure 2.

H1 (a): Individual-absorptive-capacity has a significant positive effect on cultural-fit (student-supervisor-fit)

H1 (b): Individual-absorptive-capacity has a significant positive effect on cultural-fit (student-university-fit)

$\mathrm{H} 2$ (a): Subjective-wellbeing has a significant positive effect on cultural-fit (student-supervisor-fit)

H2 (b): Subjective-wellbeing has a significant positive effect on cultural-fit (student-university-fit)

H3 (a): Cultural-fit (supervisor-fit) has a significant positive effect on academic achievement and novelty behavior

H3 (b): Cultural-fit (university-fit) has a significant positive effect on academic achievement and novelty behavior

H4: Student-university-fit has a positive effect on student-supervisor-fit

H5 (a): Cultural-fit (supervisor/university fit) has a significant indirect mediating effect on the relationship between individual-absorptive-capacity academic achievement and novelty behavior

H5 (b): Cultural-fit (supervisor/university-fit) has a significant indirect mediating effect on the relationship between subjective-wellbeing academic achievement and novelty behavior

H6: Student-supervisor-fit) has a significant indirect mediating effect on the relationship between student-university-fit and academic achievement and novelty behavior

\section{Methodology}

\subsection{Data}

In order to empirically test the hypotheses, from December 2017 to February 2018 during winter vacation, students from different cultures and region of origin (Asia, Africa, Europe, America etc) were invited to participate in this study. An online questionnaire was administered via Email and social media applications (WeChat, WhatsApp). Two versions of the online questionnaire powered by www.docs.google.com/forms and www.wjx.cn were developed for this study. The survey was confidential and anonymous. The purposeful random sampling technique was used to select respondents for the purpose of increasing credibility and not only to foster representativeness of the total population. In total, 245 finished and submitted questionnaires were retrieved from the online data sources, which approximated the intended sample size of 300 students for the study. After screening out the incomplete ones, a total of 234 valid questionnaires were used for analysis, resulting in an effective response rate of 81percent. Among those respondents, 170 (72.6percent) were male, 64 (27.4percent) were female. Regarding their age range, 31 (13.2percent) were at 18-25, 174 (74.4 percent) were at the 26-35 years range, and 29 (12.4 percent) were at the 36-50 years range. 
In terms of their student status, 108 (46.2percent) were master degree candidates and126 (53.8percent) were PhD candidates. Respondents marital status also depicted 124(53percent) as single, 94 (40.2percent) to be married, 5 ( 2.1 percent) as divorced and 11 (4.1 percent) as others. Regarding language of study and main mode of communication with faculty in the university, 193 (82.5 percent) students dialogue in English, 4 (1.9 percent) dialogues in Chinese and 36 (15.6 percent) dialogue in both English and Chinese with Faculty. Given that participants represented different home countries and cultures, respondent were grouped by region of origin. The largest representation was 128 (54.7 percent) from Asia, followed by 95 (40.6percent) from Africa, 3 (1.3 percent) from other regions and 3 (1.3 percent) from Europe, 5 (2.1percent) from America. Table 1 gives selected descriptive statistics.

Table 1. Demographics of respondents

\begin{tabular}{lll}
\hline Demographics & Frequency & Percentage \\
\hline Gender & 170 & 72.6 \\
Male & 64 & 27.4 \\
Female & & \\
Age & 31 & 13.2 \\
$18-25$ & 174 & 74.4 \\
$26-35$ & 29 & 12.4 \\
$36-50$ & & \\
Marital Status & 124 & 53 \\
Single & 94 & 40.2 \\
Married & 5 & 2.1 \\
Divorced & 11 & 4.7 \\
other & & \\
Region of Origin & 128 & 54.7 \\
Asia & 95 & 40.6 \\
Africa & 3 & 1.3 \\
Europe & 5 & 2.1 \\
America & 3 & 1.3 \\
Other & & 46.2 \\
Student Status & 108 & 53.8 \\
Master Students & 126 & \\
PhD Students & & \\
\hline
\end{tabular}

\subsection{Method}

To achieve the aim of this study, a cross-sectional design was used, supported by quantitative statistical analysis, a typical empirical paradigm. International students from University of Science and Technology of China (a C9 league university; one of Chinese government main target schools under construction up to world class standard and strategic plan to develop a number of disciplines among science, technology and education in the twenty first century) noted for its fierce competitive and innovative atmosphere were surveyed. All students were full scholarship awardees from the CAS-TWAS, Chinese Government Scholarship, CAS Belt and Road Master Fellowship and University Scholarship. Students are required to publish at least 1 article for master and 2 articles for $\mathrm{PhD}$ in renowned academic journals with indexes in SCI, SSCI and other few selected journals before graduation from the 3year master and 4year doctoral research programs. To measure the predictor and outcome variables, an instrument was developed for both the latent and observed variables namely individual-absorptive-capacity, subjective-wellbeing, cultural-fit and academic achievement; all of which were combined into a proposed academic achievement and novelty behavior model. This served as the motivation to select structural equation modeling (SEM) as the appropriate method of analysis. Accordingly a sample size for complex SEM should be more than 100. (Kline 2005). 


\subsection{Measures}

Individual-Absorptive-Capacity: A fourteen-item scale developed by Lowik et al.'s (2016), Cohen and Levinthal (1990), was modified to measure individual-absorptive-capacity. It was intended to be operationalized as a second-order construct consisting of individual activities of recognition, assimilation \& transformation and exploitation. Measures were rated on a five-point Likert-type scale, and response options ranged from 1, "strongly disagree," to 5, "strongly agree." A sample item is: "I am always actively looking for new knowledge for my research work"

Subjective-wellbeing: A six-item scale developed by Hills and Argyle (2002) was used to measure subjective-wellbeing. Measures were rated on a five-point Likert-type scale, and response options ranged from 1, "strongly disagree," to 5, "strongly agree." A sample item is: "I am very happy."

Cultural-fit: A twelve-item scale adopted and modified from Aichia Chuang et al (2016)was used to measure cultural-fit. Two dimensions of Perceived-Person-Environment-Fit Scale (PPEFS) person-organization-fit and person-supervisor-fit was used because it suited the present study's context. Cultural-fit was therefore operationalized as first order two dimensional constructs consisting of the Variables University-fit and Supervisor-fit. Measures were rated on a five-point Likert-type scale, and response options ranged from 1, "extremely unlikely," to 5, "extremely likely." A sample item is: "How would you describe the match between your research passions and your supervisor's research area and expertise?

Academic-Achievement-Novelty: A measure of six-item scale adapted from Zhou and George (2001) and general graduation requirements were used to measure the outcome variable; perceived-academic-achievement and novelty. Measures were rated on a five-point Likert-type scale, and response options ranged from 1, "strongly disagree," to 5, "strongly agree." A sample item is: "I come up with new and practical ideas to improve academic performance".

Demographics: for this study, age, gender, marital status, mode of study, region of origin, student's status, type of scholarship, field of research, religious beliefs, dynamic atmosphere and research challenges were selected as demographics. Gender was dummy coded (1="male" and $0=$ "female"), while age was measured using a 3-point scale $(1=$ "18-25)", $(2=26-35)$ and $(3=36-50)$. Dynamism was measured using five point Likert type scale. Research challenges measured with multiple response items. Table 1 and Fig 2 presents further detailed demographics of respondents. 


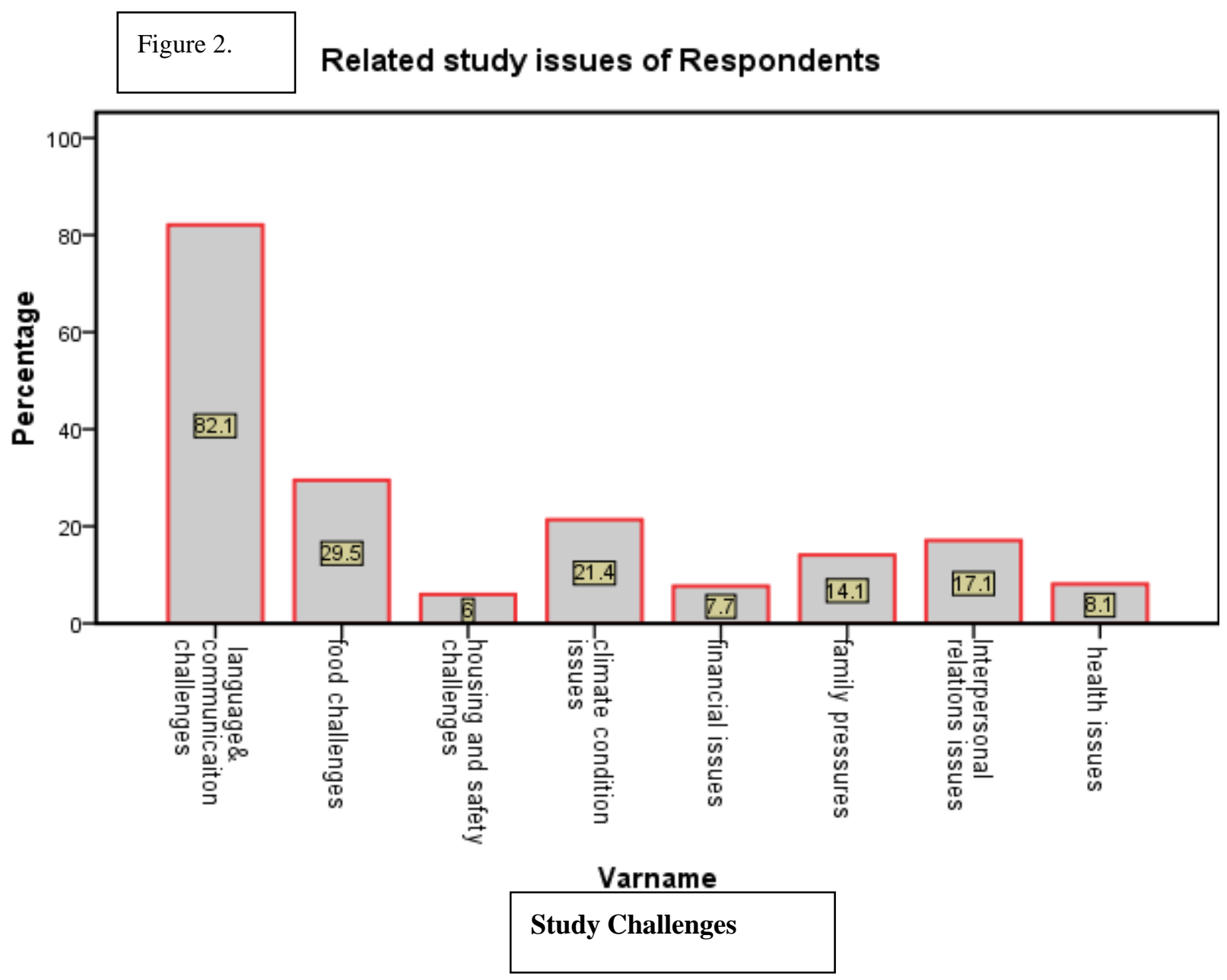

\section{Analysis and Results}

\subsection{Step 1}

In the present study, first exploratory factor analysis was used to deal with dimension reduction of items. In doing so, we aimed to obtain a reduced number of factors, enabling the identification of structural relations between predictor and outcome variables. The method used for extracting the factors was the principal component method, through the Promax with Kaiser Normalization approach. In accordance with the Scree Plot and the retained variance percentage, 7 factors were retained registering an eigen-value greater than 1, explaining $66.584 \%$ of total variance extracted, significant at 0.00 level with KMO and Bartlett's Test of 0.908 and Chi square 5.648E3, $\mathrm{df}=666$ respectively (Hair et al. 2005). Items were suppressed at 4.0 threshold which resulted in one item "capacity10" being dropped. The remaining items were used for further factor validation purposes. Table 2 presents the results of Exploratory Factor Analysis. 
Table 2. Exploratory Factor Analysis in SPSS

\begin{tabular}{|c|c|c|c|c|c|c|c|}
\hline Items & Component & & & & & & \\
\hline loading & 1 & 2 & 3 & 4 & 5 & 6 & 7 \\
\hline$\overline{\text { Cfit4 }}$ & .808 & & & & & & \\
\hline Cfit2 & .808 & & & & & & \\
\hline Cfit3 & .805 & & & & & & \\
\hline Cfit7 & .791 & & & & & & \\
\hline Cfit1 & .778 & & & & & & \\
\hline Cfit6 & .761 & & & & & & \\
\hline Cfit5 & .743 & & & & & & \\
\hline Wellbing4 & & .874 & & & & & \\
\hline Wellbing2 & & .816 & & & & & \\
\hline Wellbeing6 & & .727 & & & & & \\
\hline Wellbeing1 & & .697 & & & & & \\
\hline Wellbeing5 & & .687 & & & & & \\
\hline Wellbeing3 & & .656 & & & & & \\
\hline Novelty3 & & & .861 & & & & \\
\hline Noveltyt5 & & & .794 & & & & \\
\hline Novelty2 & & & .703 & & & & \\
\hline Noveltyt6 & & & .681 & & & .411 & \\
\hline Novelty4 & & & .673 & & & & \\
\hline Novelty1 & & & .587 & & & & \\
\hline capacity5 & & & & .758 & & & \\
\hline capacity8 & & & & .732 & & & \\
\hline capacity7 & & & & .714 & & & \\
\hline capacity6 & & & & .663 & & & \\
\hline capacity 9 & & & & .659 & & & \\
\hline capacity12 & & & & & .840 & & \\
\hline capacity11 & & & & & .813 & & \\
\hline capacity14 & & & & & .676 & & \\
\hline capacity13 & & & & & .672 & & \\
\hline Cfit9 & & & & & & .783 & \\
\hline Cfit10 & & & & & & .727 & \\
\hline Cfit12 & & & & & & .655 & \\
\hline Cfit8 & & & & & & .639 & \\
\hline Cfit11 & & & & & & .525 & \\
\hline capacity1 & & & & & & & .785 \\
\hline capacity3 & & & & & & & .774 \\
\hline capacity 2 & & & & & & & .724 \\
\hline capacity4 & & & & & & & .482 \\
\hline
\end{tabular}

Extraction Method: Principal Component Analysis. Rotation Method: Promax with Kaiser Normalization. a. Rotation converged in 8 iterations. 
To test the validity of data, reliability test was run. At the same time, we used a powerful instrument that could analyze the confirmatory factor analysis, regression and structural model simultaneously to estimate measurement model (Anderson \&Gerbing, 1988).Furthermore, standardized factor loadings, squared multiple correlations (SMC) and model fit indices were considered to be the key statistical criteria for an acceptable measurement model (Koufteros, 1999). Threshold level for Cronbach's alpha, composite reliability, average variance extracted (AVE), standardized factor loadings and squared multiple correlations-SMC $\left(\mathrm{R}^{2}\right)$ is $0.7,0.7,0.5,0.7$ and 0.5 respectively, as per the standard criteria in existing literature (Flynn, Sakakibara, Schroeder, Bates, \& Flynn, 1990; Fornell\&Larcker, 1981; Hair et al., 1998; Nunally\& Bernstein, 1978; Bollen, 1989; Lu et al., 2007; Garver and Mentzer, 1999). With respect to standardized factors loadings and SMC, lower values have been considered acceptable depending on sample size and for interpretive purposes (Hair et al 1998; Stevens 1992; Tabachnick and Fidell 2007).

As presented in Table 3, composite reliability and Cronbach's alpha values are greater than 0.7 and AVE values for all constructs are greater than 0.5 confirming good convergent validity. In terms of discriminate validity Fornell and Larcker (1981), suggests anassessment of the relationship between correlation among the constructs and the square root of AVE of all constructs. In the instance where square root of AVE is higher than the correlation among constructs, then good discriminate validity is confirmed (see Table 4). 
Table 3. Result of Confirmatory Factor Analysis, Cronbach's Alpha, Composite Reliability (CR), and Average Variance Extracted (AVE)

\begin{tabular}{|c|c|c|c|c|c|}
\hline Constructs & Factor loadings & SMC (R-square) & Cronbach's Alpha & (CR) & (AVE) \\
\hline Novelty Achievement & & & 0.863 & 0.866 & 0.521 \\
\hline Novelty1 & 0.675 & 0.456 & & & \\
\hline Novelty 2 & 0.658 & 0.433 & & & \\
\hline Novelty3 & 0.756 & 0.571 & & & \\
\hline Novelty4 & 0.771 & 0.594 & & & \\
\hline Novelty5 & 0.774 & 0.599 & & & \\
\hline Novelty6 & 0.686 & 0.471 & & & \\
\hline Cultural Fit & & & 0.940 & & \\
\hline Scfit & & & 0.895 & 0.895 & 0.631 \\
\hline Cfit8 & 0.738 & 0.545 & & & \\
\hline Cfit9 & 0.807 & 0.651 & & & \\
\hline Cfit10 & 0.909 & 0.549 & & & \\
\hline Cfit11 & 0.741 & 0.586 & & & \\
\hline Cfit12 & 0.765 & 0.636 & & & \\
\hline Ucfit & & & 0.929 & 0.921 & 0.627 \\
\hline Cfit1 & 0.763 & 0.582 & & & \\
\hline Cfit2 & 0.799 & 0.638 & & & \\
\hline Cfit3 & 0.816 & 0.666 & & & \\
\hline Cfit4 & 0.771 & 0.595 & & & \\
\hline Cfit5 & 0.868 & 0.754 & & & \\
\hline Cfit6 & 0.720 & 0.518 & & & \\
\hline Cfit7 & 0.797 & 0.636 & & & \\
\hline Subjective well-being(SWB) & & & 0.884 & 0.888 & 0.575 \\
\hline Wellbeing1 & 0.827 & 0.683 & & & \\
\hline Wellbeing2 & 0.797 & 0.636 & & & \\
\hline Wellbeing3 & 0.761 & 0.579 & & & \\
\hline Wellbeing4 & 0.788 & 0.621 & & & \\
\hline Wellbeing5 & 0.515 & 0.265 & & & \\
\hline Wellbeing6 & 0.815 & 0.665 & & & \\
\hline Overall Capacity(IAC) & & & 0.870 & 0.843 & 0.645 \\
\hline Cap Recognition & 0.678 & 0.46 & 0.709 & & \\
\hline Capacity1 & 0.557 & 0.310 & & & \\
\hline Capacity2 & 0.639 & 0.408 & & & \\
\hline Capacity3 & 0.563 & 0.317 & & & \\
\hline Capacity4 & 0.684 & 0.469 & & & \\
\hline CapAssimTrans & 0.867 & 0.752 & 0.811 & & \\
\hline Capacity5 & 0.736 & 0.542 & & & \\
\hline Capacity6 & 0.785 & 0.616 & & & \\
\hline
\end{tabular}




\begin{tabular}{lll}
\hline Capacity7 & 0.668 & 0.446 \\
Capacity8 & 0.702 & 0.492 \\
Cap Exploitation & $\mathbf{0 . 8 5}$ & $\mathbf{0 . 7 2 3}$ \\
Capacity11 & 0.787 & 0.620 \\
Capacity12 & 0.777 & 0.604 \\
Capacity13 & 0.831 & 0.690 \\
Capacity14 & 0.641 & 0.410
\end{tabular}

Table 4. Descriptive Statistics, Correlation Matrix, Convergent and Discriminant Validity

\begin{tabular}{llllllll}
\hline Constructs & Mean & Std. Deviation & $\mathbf{1}$ & $\mathbf{2}$ & $\mathbf{3}$ & $\mathbf{4}$ & $\mathbf{5}$ \\
\hline Dynamism & 4.17 & 0.72 & & & & & \\
Cap Recognition & 3.96 & 0.53 & & & & & \\
CapAssimTrans & 3.87 & 0.56 & & & & & \\
Cap Exploitation & 4.13 & 0.55 & & & & & \\
Novelty Achievement & 4.49 & 0.51 & $\mathbf{0 . 7 2 2}$ & & & & \\
Scfit & 3.82 & 0.78 & 0.600 & $\mathbf{0 . 7 9 5}$ & & & \\
Ucfit & 4.08 & 0.71 & 0.631 & 0.77 & $\mathbf{0 . 7 9 2}$ & & \\
SWB & 4.03 & 0.62 & 0.679 & 0.728 & 0.641 & $\mathbf{0 . 7 5 8}$ & \\
Overall Capacity (IAC) & 3.98 & 0.44 & 0.536 & 0.538 & 0.369 & 0.454 & $\mathbf{0 . 8 0 3}$ \\
Boldface in diagonal line shows square root of AVE of each construct. & & & \\
Correlation is significant at .01 levels.
\end{tabular}

4.2 Step 2

Structural equation model as a cross-discipline research tool has received much attention recently and become one of the important techniques applied by scholars to validate their research results (Hooper, Coughlan, \& Mullen, 2008). To evaluate the model fitness, researchers suggest the examination of fitness indices such 1. Absolute-fits; affected by sample size (e.gchi-square, goodness of fit index (GFI), adjusted goodness of fit index (AGFI), root mean square error of approximation (RMSEA) etc) McDonald and Ho, 2002 and 2. Incremental-fit; i.e. group of indices that do not use the chi-square in its raw form but compare the chi-square value to a baseline model (tucker-lewis index (TLI), comparative fit index (CFI), Normed-fit index (NFI) etc.(Miles and Shevlin, 2007; Jöreskog and Sörbom, 1993). The present study follows acceptable threshold fit indices recommended by previous researchers to determine model goodness; Chi-square <3.0, GFI >0.90, AGFI >0.80, RMSEA<0.07, PCLOSE >0.05 (Hu and Bentler 1999; Miles and Shevlin 2007; Arbuckle 2003), Other researchers recommended that for TLI, IFI, CFI, and NFI, indices the values can be greater than 0.85 (Arbuckle, 2003; Hu \&Bentler, 1999).

As per the aforementioned recommendations, indices calculated for this study shown the appropriate goodness-of-fit for the measurement and the structural model where all values of chi-square, GFI, AGFI, CFI, TLI, NFI, IFI, and RMSEA are within acceptable threshold range as shown in Tables 5 and 6.

Table 5. Goodness of Fit Indices for Measurement Model.

\begin{tabular}{llllllllllll}
\hline Model & X2 & df & p-value & X2/df & GFI & AGFI & RMSEA & UPCLOSE & CFI & IFI & NFI \\
\hline Base & 927.601 & 563 & 0.000 & 1.648 & 0.834 & 0.804 & 0.053 & 0.227 & 0.930 & 0.931 & 0.841 \\
\hline
\end{tabular}

Table 6. Goodness of Fit Indices for Structural Model.

\begin{tabular}{llllllllllll}
\hline Model & X2 & df & p-value & X2/df & GFI & AGFI & RMSEA & UPCLOSE & CFI & IFI & NFI \\
\hline Base & 650.173 & 409 & 0.000 & 1.590 & 0.858 & 0.828 & 0.050 & 0.464 & 0.948 & 0.948 & 0.872 \\
\hline
\end{tabular}




\subsection{Discussion}

The primary aim of this study was to examine the impact of student's absorptive capacity and subjective-wellbeing in predicting their academic achievement and novelty behavior; by specifically positing cultural-fit dimensions as important mediators. Students are under much pressure with dissertation and publishing of scholarly articles forming a significant part of the final degree award in recent times (Hand and Clewes, 2000). Success factors in the retention and completion of postgraduate students have been studied by some researchers in different context (Grant \& McKinley, 2011; Trudgett 2014; Trudgett et al., 2016; McKinley, Grant, Middleton, Irwin, \& Williams, 2011).Therefore, boosting up their cognitive, psychological and social capabilities is the key to structural reform which can motivate them at a deeper level to achieve novelty and sustainable research productivity. University administrators, policymakers, and educators should focus on reforming educational programs and should provide students with practical education and training as well as conducive atmosphere(Xiao-jiong 2010)in order to enhance their capabilities and skills to fulfill new models of postgraduate awarding requirements at their candidature level.In today's increasingly competitive academic workforce, a healthy list of scholarly publications is necessary for job applications, funding applications and internal promotions (Dinham\& Scott, 2001; Brien, 2008). Publishing standards set by various C9 Chinese university and other higher institutions around the globe for their studentsis taught to aim at preparing them for the skills andknowledge that will better facilitate an active and sustainable career in academia (Smith, 2015; PoyatosMatas, 2012). This may account many benefits to students and their hostinstitutions. Previous studies have shown that students who publish early in their careers, during their postgraduatestudies, are more likely to have greater research productivitythroughout their careers (Fischer, Ritchie, \&Hanspach, 2012; Horta\& Santos, 2015). Research outputs are a key measure of the success of institutions (Australian Research Council, 2016) and specifically the quantum of fundinguniversities receive from government is dependent on how many publications, patentsand innovationstheir academics produce (Norton, 2016).

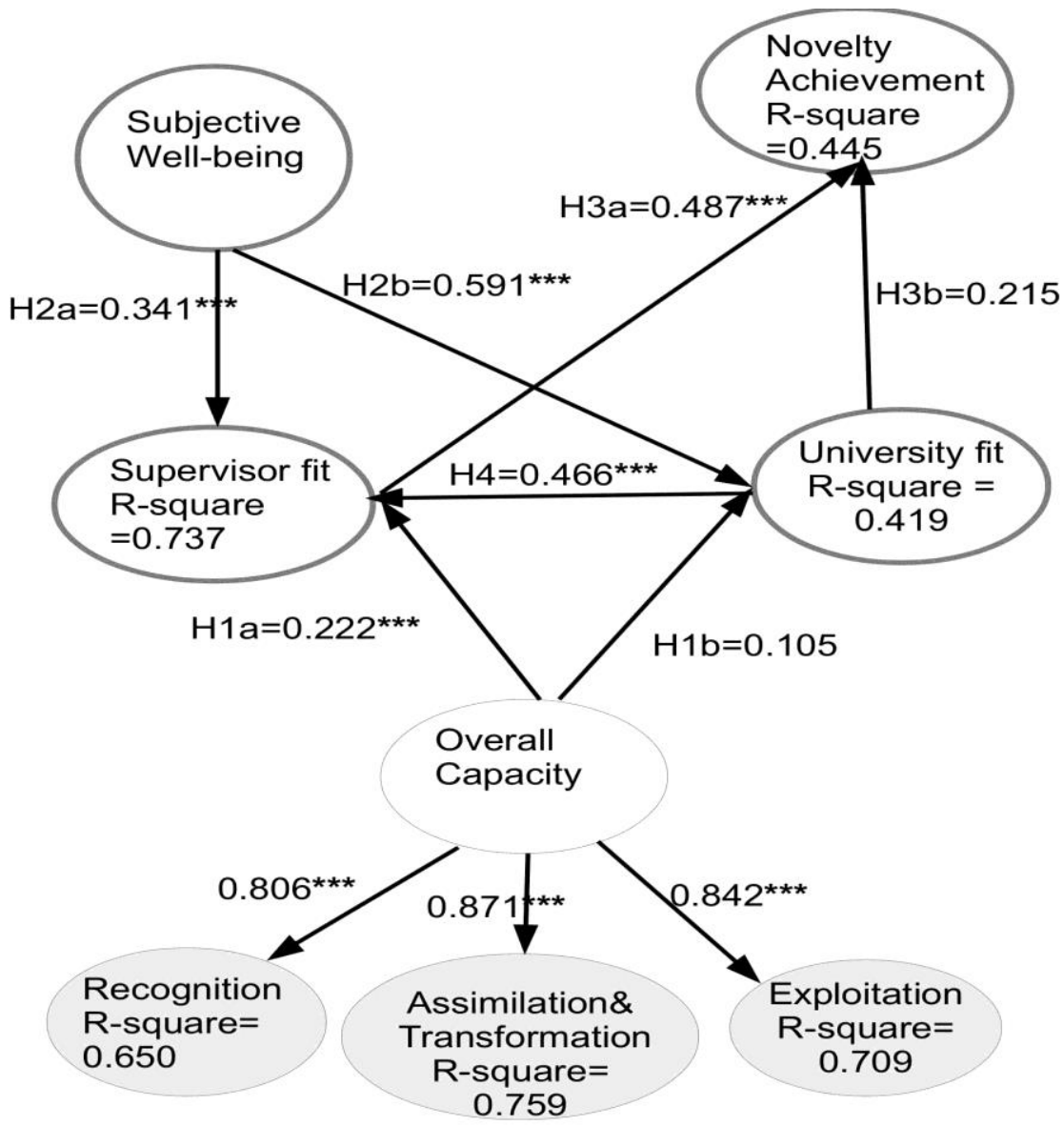

Fig 3. Results of structural model. ${ }^{*} \mathrm{P}<0.05$, ${ }^{* *} \mathrm{P}<0.01$, ${ }_{* * * P}<0.001$, Overall capacity represented as higher order construct and university/supervisor fit as formative of Cultural fit. 
The present study findings show that individual-absorptive-capacity has a positive significant impact on supervisor-fit butnon-significant impact university-fit dimensions of cultural-fit. Subjective-wellbeing also showed also showed a positive significant impact on both supervisor-fit and university-fit. The supervisor-fit is found to be positively associated academic achievement and novelty behavior. Similarly, supervisor-fit is positively influenced by university-fit. University-fitis also found to be positivelyassociated with academic achievement and novelty but it has non-significant value. The findings further show how supervisor-fit and university-fit indirectly mediate the relationships between both (individual-absorptive-capacity and subjective-wellbeing) and academic achieve and novelty behavior by way of bootstrapping. In hypothetical terms our study finds support for H1(a), H2(a), H2 (b), H2 (b), H3 (a), H4, H5 (a), H5 (b) and H6 but no support for H1(b) and H3(b). This is the first empirical study testing a causal model that predicts student's academic achievements and research novelty considering the direct and indirect influence of absorptive capacity, subjective well-being and cultural fit dimensions in China.

Table 7. Results of Hypothesis Testing (direct \& indirect mediation effects)

\begin{tabular}{llll}
\hline Hypothesis & Regression paths & Std. Estimates & Remarks \\
\hline H1(a) direct effect & Overall capacity $\rightarrow$ supervisor fit & $0.222^{* * *}$ & accepted \\
H1(b) direct effect & Overall capacity $\rightarrow$ university fit & 0.105 & rejected \\
H2(a) direct effect & Subjective well-being $\rightarrow$ supervisor fit & $0.341^{* * *}$ & accepted \\
H2 (b) direct effect & Subjective well-being $\rightarrow$ university fit & $0.591^{* * *}$ & accepted \\
H3 (a) direct effect & supervisor fit $\rightarrow$ novelty achievement & $0.487^{* * *}$ & accepted \\
H3(b) direct effect & University fit $\rightarrow$ novelty achievement & 0.215 & rejected \\
H4 direct effect & University fit $\rightarrow$ supervisor fit & $0.466^{* * *}$ & accepted \\
H5 (a) indirect effect & Overall capacity $\rightarrow$ novelty achievement & $0.155^{* * *}$ & accepted \\
H5 (b) indirect effect & Subjective well-being $\rightarrow$ novelty achievement & $0.428^{* * *}$ & accepted \\
H6 indirect effect & University fit $\rightarrow$ novelty achievement & $0.227^{* * *}$ & accepted \\
\hline
\end{tabular}

${ }^{*} \mathbf{p}<0.05, * * \mathbf{p}<0.01, * * * p<0.001 ;$ Bootstrap samples 500; BC confidence level 95\%

Our study makes important implications by focusing on the postgraduate foreigner'sacademic achievement, research productivity, innovation, adaptation issues, and fulfillment of new graduation modelsin higher education settings at the individual level. First, the individuals reflect very basic, but important research unites that can be readily observed. Furthermore, to our knowledge, little is known about international student's academic achievement and novelty, especially what factors influence these activities, which can enrich our understanding of their success in the Host universities. Secondly, absorptive capacity and subjective-wellbeing factors considered in this study have its basis in individual actions, behaviors and predispositions as valuable capital (Brehm and Rahn, 1997).It is not clear about the influence mechanism of different predictors on academic achievement, and we try to fill this gap. Thirdly, we advance the person-environment-fit research at the individual level by firstly exploring the mediating role of cultural-fit. We recognize that student's achievement and novelty are driven by the aggregation of numerous fit factors (supervisor and university fit). In other words, we provide a further understanding of antecedents and consequences of individual-cultural-fit.

Even though, students are encouraged and required to publish scholarly articles in addition to their course work and thesis to be eligible for degree awards, they are however also warned of pitfalls and challenges, including risks to the coherence and integrity of the thesis, publication delay and coldreviewers especially in the SSCI/ SCI index journals as well as most renowned indexes. Also orbit times for the peer-review process are infamously long and getting longer (Powell, 2016). This can affect a student's ability to complete their thesis in a timely manner. It is worth noting that Universities have different policies regarding the status of papers permitted to be considered for graduation. While some require papers to be published in high index journals or in-press, others allow papers to be under review or papers which have been prepared for submission.

Finding from this study indicate that Absorptive capacity is an important determinant of students achievement and novelty which approves the fact that cognitive capabilities as a necessity for postgraduate education. The results also show that student's have high sense of subjective wellbeing which greatly influence theirachievement and noveltybehavior. Moreover, the results of the study indicate that cultural fit (supervisor and university fit) can play an important role in developing favorable research and valuable intellectual assets among students toward their 
achievements in host universities. Surprisingly the results revealed that, students cannot fit better in their host university whiles striving to achieve success without them fitting with their supervisor/mentors. In other words, supervisor fit guarantees more success than university fit for international student'sacademic success.

Overall, the findings shows that students posses high absorptive capacityand are well positively psyched in their wellbeing as they thrive for achievement, but there are cultural-fit pressures that create a better enhancement to their achievement and productivity.

\subsection{Limitations and Future Direction}

There are some limitations to this study. It is worth noting that absorptive capacity, subjective-wellbeing and cultural fit are not the only cognitive, physiological and person-environment-fit factors that might influence students academic achievement and novelty; therefore, other factors might merit consideration as predictors of students academic achievement and novelty especially in today's digital and diverse higher education context. Although absorptive capacity was treated as a second higher order construct, there was a little deviation from established theory which reflects four independent factors;recognition, assimilation, transformation and exploitation based on Lowik et al.'s (2016), and Cohen and Levinthal (1990); our data revealed three factors therefore the corresponding findings should be interpreted accordingly. Finally, participants in this cross-sectional study were all 2016/2017 bath of international postgraduate students immersed in a critical transition period from adaptations to their new study country, to balancing lifestyle changes and fulfilling the challenging requirements for graduation in Host University, which implies a combination cognitive,psychological, socio-cultural and academic adjustments (Fryer 2017, María et.al 2006). However, changes across the lifetime of their degree pursuit in the variables defining the proposed hypothesized model were not addressed.

Despite these potential limitations, further studies are needed to advance this research line by (i) exploring other important and reliable predictor variables probably to academic achievement (e.g., academic self-efficacy, self-worth and transformation, motivation, social communication, leaning effort, social capital developed through campus associations(Rhew et.al, 2018; Glass et. al 2018; Li et.al 2010; Kelly et.al 2018)(ii) examining in depth absorptive capacity as a first order construct using different scales (Seo, et.al 2015; Jansen et al. 2005) (iii) performing longitudinal studies (Pampaka et. al 2016)with multiple waves to address these relationships over time, tandem with qualitative and or from a person-oriented perspective as well as expanding the scope of study to include samples (both local and international students) from all C9 universities in China and other countries.

\section{Conclusion}

In sum, this research advances the current understanding of the density of international students' learning experience in higher education settings, research productivity, and the international higher education market by providing empirical evidence for a causal model linking absorptive capacity, subjective-wellbeing, cultural fit and achievement $\&$ novelty. These findings hold substantive implications for researchers seeking an integrative view of postgraduate students' learning experience and novelty especially in overseas study and are relevant to superiors and university management wanting to foster an optimal dynamic-learning environment in which students can well be inducted about their learning and teaching needs (Nallaya, S. S. 2018)whilesfulfilling required standards for degrees and produce novelty.

\section{Acknowledgement}

Grateful thanks are due Professor Song Wei, and his assistant Zhao Shu Liang (PhD) for providing helpful comments on the survey development. Warm appreciation to the Chinese Government Scholarship Council for providing the corresponding author with study grants to pursue his postgraduate studies at the University of Science and Technology of China (USTC).

\section{References}

Abbott-Chapman, J., Hughes, P., \& Wyld, C. (1992). Monitoring student progress: A framework for improving student performance and reducing attrition in higher education. Hobart: National Clearinghouse for Youth Studies.

Al Farra, Samia. (2012). School Culture and Students' Achievement. IB the Culture of Learning Madrid. Dubai, United Arab Emirates.https://doi.org/10.1016/j.intman.2005.03.011

Anderson, J. C., \& Gerbing, D. W. (1988). Structural equation modeling in practice: A review and recommended two-step approach. Psychological bulletin.https://doi.org/10.1037/0033-2909.103.3.411 
Allred.B \& Swan S. (2005). The mediating role of innovation on the influence of industry structure and national context on firm performance.Journal of International Management.https://doi.org/10.1016/j.intman.2005.03.011

Ames, C. (1978). Children's achievement attributions and self-reinforcement; effects of self-concept and competitive reward structure. Journal of Educational Psychology.https://doi.org/10.1037/0022-0663.70.3.345

Asteris, M. (2006). British universities: The "coal exporters" of the 21st century. Journal of Studies in International Education.https://doi.org/10.1177/1028315306289785

Australian Research Council. (2016). Annual report 2015-16.

Barney, K. (2018). 'We need more mob doing research': developing university strategies to facilitate successful pathways for Indigenous students into Higher Degrees by Research. Higher Education Research \& Development.https://doi.org/10.1080/07294360.2018.1467382

Bennett, S. (2003). Cultural identity and academic achievement among Māori undergraduate university students. Proceedings of the national Māori graduates of psychology symposium.

Bollen, K. A. (1989). A new incremental fit index for general structural equation models. Sociological Methods \& Research.https://doi.org/10.1177/0049124189017003004

Böhm, A., Follari, M., Hewett, A., Jones, S., Kemp, N., Meares, D., et al. (2004). Forecastinginternational student mobility - A UK perspective. London: British Council,Universities UK and IDP Education.

Brehm, J., \& Rahn, W. (1997). Individual-level evidence for the causes and consequences of social capital. American journal of political science.https://doi.org/10.2307/2111684

Brien, D. L. (2008). Publish or perish? Investigating the doctorate by publication in writing. In D. L. Brien \& L. Neave (Eds.), Creativity and uncertainty.

Cano, F., Martin, A. J., Ginns, P., \& Berbén, A. B. G. (2017). Students' self-worth protection and approaches to learning in higher education: predictors and consequences. Higher Education.https://doi.org/10.1007/s10734-017-0215-0

Carter, S. C. (2011). How Great School Cultures Form Strong Character. Thousand Oaks, CA: Corwin Press.

Crookes, P. A., Outram, S., \& Else, F. C. (2018). Developing a collaborative pilot programme to promote innovation in higher education focusing on the reward and recognition of teaching. Journal of Further and Higher Education.https://doi.org/10.1080/0309877X.2017.1349890

Chuang, A., Shen, C. T., \& Judge, T. A. (2016). Development of a multidimensional instrument of personenvironment fit: The Perceived Person-Environment Fit Scale (PPEFS). Applied Psychology.https://doi.org/10.1111/apps.12036

Chuang, A., \& Sackett, P. R. (2005). The perceived importance of person-job fit and person-organization fit between and within interview stages. Social Behavior and Personality. https://doi.org/10.2224/sbp.2005.33.3.209

Cohen, W. M. and Levinthal, D. A. (1990). Absorptive-Capacity - A New Perspective on Learning and Innovation. Administrative Science Quarterly.https://doi.org/10.2307/2393553

Cohn, M. A., Fredrickson, B. L., Brown, S. L., Mikels, J. A., \& Conway, A. M. (2009). Happiness unpacked: positive emotions increase life satisfaction by building resilience. Emotion.https://doi.org/10.1037/a0015952

Da Silva, N., \& Davis, A. R. (2011). Absorptive capacity at the individual level: Linking creativity to innovation in academia. The review of higher education.https://doi.org/10.1353/rhe.2011.0007

Derounian, J. (2011). Shall we dance? The importance of staff-student relationships to undergraduate dissertation preparation. Active Learning in Higher Education.https://doi.org/10.1177/1469787411402437

DiMarco, N. (1974). Supervisor-subordinate life style and interpersonal need compatibilities as determinants of subordinate's attitudes toward the supervisor. Academy of Management Journal.https://doi.org/10.2307/254661

Ding, X. (2016). Exploring the experiences of international students in China. Journal of Studies in International Education.https://doi.org/10.1177/1028315316647164

Dinham, S., \& Scott, C. (2001). The experience of disseminating the results of doctoral research. Journal of Further and Higher Education.https://doi.org/10.1080/03098770020030498

Elbot, Charles F \& Fulton, D. (2008). Building an Intentional School Culture: Excellence in Academics and 
Character. Thousand Oaks, CA: Corwin Press.

Edgar, F., \&Geare, A. (2013). Factors influencing university research performance. Studies in Higher Education. https://doi.org/10.1080/03075079.2011.601811

Flynn, B. B., Sakakibara, S., Schroeder, R. G., Bates, K. A., \& Flynn, E. J. (1990). Empirical research methods in operations management. Journal of operations management.https://doi.org/10.1016/0272-6963(90)90098-X

Fornell, C., \& Larcker, D. F. (1981). Structural equation models with unobservable variables and measurement error: Algebra and statistics. Journal of marketing research.https://doi.org/10.2307/3151312

Fischer, J., Ritchie, E. G., \& Hanspach, J. (2012). Academia's obsession with quantity. Trends in Ecology and Evolution.https://doi.org/10.1016/j.tree.2012.05.010

Francesca, L \& Gary, P. P (2014). The Organizational and Geographic Drivers of Absorptive Capacity: An Empirical Analysis of Pharmaceutical R\&D Laboratories Harvard Business School Working.

Freel,M. "Perceived environmental uncertainty and innovation in small firms," Small Business Economic.

Fryer, L. K. (2017). (Latent) transitions to learning at university: a latent profile transition analysis of first-year Japanese students. Higher Education. https://doi.org/10.1007/s10734-016-0094-9

Garver, M. S., \&Mentzer, J. T. (1999). Logistics research methods: employing structural equation modeling to test for construct validity. Journal of business logistics.

Grant, B., \& McKinley, E. (2011). Colouring the pedagogy of doctoral supervision: Considering supervisor, student and knowledge through the lens of indigeneity. Innovations in Education and Teaching International.https://doi.org/10.1080/14703297.2011.617087

Glass, C. R., \& Gesing, P. (2018). The Development of Social Capital Through International Students' Involvement in Campus Organizations. Journal of International Students.

Grobler, A., \& Rensburg, M. J. V. (2018). Organisational climate, person-organisation fit and turn over intention: a generational perspective within a South African Higher Education Institution. Studies in Higher Education.https://doi.org/10.1080/03075079.2018.1492533

Head, P. (1990). Performance Indicators and Quality Assurance, Council for National Academic Awards, London.

Hair, J. F., Anderson, R. E., Tatham, R. L., \& Black, W. C. (1998). Multivariate data analysis. 1998. Upper Saddle River

Hand L \& Clewes D. (2000). Marking the difference: An investigation of the criteria used for assessing undergraduate dissertations in a business school. Assessment and Evaluation in Higher Education.https://doi.org/10.1080/713611416

Haas, B. W. (2018). The impact of study abroad on improved cultural awareness: a quantitative review. Intercultural Education.https://doi.org/10.1080/14675986.2018.1495319

Hills, P., \& Argyle, M. (2002). The Oxford Happiness Questionnaire: A compact scale for the measurement of psychological well-being. Personality and Individual Differences.https://doi.org/10.1016/S0191-8869(01)00213-6

Hooper, D., Coughlan, J., \& Mullen, M. (2008). Structural equation modelling: Guidelines for determining model fit. Articles.

Ingraham, E. C., \& Peterson, D. L. (2004). Assessing the impact of study abroad on student learning at Michigan State University. Frontiers.

Jean-Francois, E. (2017). Exploring the perceptions of campus climate and integration strategies used by international students in a US university campus. Studies in Higher Education.https://doi.org/10.1080/03075079.2017.1416461

Juanru Wang \& Jin Yang. (2017). Subjective well-being, knowledge sharing and individual innovation behavior.The moderating role of absorptive capacity. Leadership \& Organization Development Journal.https://doi.org/10.1108/LODJ-10-2015-0235

Kelly, A., Bennett, D., Giridharan, B., \& Rosenwax, L. (2018). Study experiences and the post-study intentions of female international undergraduate students. Asia Pacific Journal of Education.https://doi.org/10.1080/02188791.2018.1460256 
Koufteros, X. A. (1999). Testing a model of pull production: a paradigm for manufacturing research using structural equation modeling. Journal of Operations Management.https://doi.org/10.1016/S0272-6963(99)00002-9

Kline RB. (2005).Principles and practice of structural equation modeling. The Guilford Press.

KouroshAmrai, ShahrzadElahiMotlagh, HamzehAziziZalani \& HadiParhon. (2011). The relationship between academic motivation and academic achievement students. Procedia Social and Behavioral Sciences.

Kristof-Brown, A. L., \& Guay, R. P. (2011). Person-environment fit. In S. Zedeck (Ed.), American Psychological Association handbook of industrial and organizational psychology.https://doi.org/10.1037/12171-001

Kristof-Brown, A. L., \& Stevens, C. K. (2001). Goal congruence in project teams: Does the fit between members' personal mastery and performance goals matter? Journal of Applied Psychology. https://doi.org/10.1037/0021-9010.86.6.1083

Kristof-Brown, A. L., Jansen, K. J., \& Colbert, A. E. (2002). A policy-capturing study of the simultaneous effects of fit with jobs, groups, and organizations. Journal of Applied Psychology. https://doi.org/10.1037/0021-9010.87.5.985

Kristof-Brown, A. L., Zimmerman, R. D., \& Johnson, E. C. (2005). Consequences of individuals' fit at work: A meta-analysis of person-job, person-organization, person-group, and person-supervisor fit. Personnel Psychology.https://doi.org/10.1111/j.1744-6570.2005.00672.x

Kulik, C. T., Oldham, G. R., \& Hackman, J. R. (1987). Work design as an approach to person-environment fit. Journal of Vocational Behavior.https://doi.org/10.1016/0001-8791(87)90044-3

Leask, B., \& Carrol, J. (2011). Moving beyond 'wishing and hoping': Internationalisation and student experiences of inclusion and Higher Education Research \& Development.https://doi.org/10.1080/07294360.2011.598454

Li, G., Chen, W., \& Duanmu, J. L. (2010). Determinants of international students' academic performance: A comparison between Chinese and other international students. Journal of Studies in International Education.

Lowik, S., Lowik, S., Kraaijenbrink, J., Kraaijenbrink, J., Groen, A., \& Groen, A. (2016). The team absorptive capacity triad: a configurational study of individual, enabling, and motivating factors. Journal of knowledge management.https://doi.org/10.1108/JKM-11-2015-0433

Lowik, S., Lowik, S., Kraaijenbrink, J., Kraaijenbrink, J., Groen, A. J., \& Groen, A. J. (2017). Antecedents and effects of individual absorptive capacity: a micro-foundational perspective on open innovation. Journal of knowledge management.https://doi.org/10.1108/JKM-09-2016-0410

Luigi, A., Maxim, K. \& Concetto, P. V. (2017). The impact of research collaboration on academic performance: An empirical analysis for some European countries. Socio-Economic Planning Sciences.

Ma, J. (2017). Why and how international students choose mainland China as a higher education study abroad destination? Higher Education.https://doi.org/10.1007/s10734-016-0066-0

Ma, J., \& Wen, Q. (2018). Understanding international students' in-class learning experiences in Chinese higher education institutions. Higher Education Research \& Development.https://doi.org/10.1080/07294360.2018.1477740

Mayeda,D. T., Keil, M.A.,Dutton, D.H., \& 'Ofamo'oni, I. F. H. (2014). "You've gotta set a precedent”: Māori and Pacific voices on student success in higher education. AlterNative.https://doi.org/10.1177/117718011401000206

Marini, A. Journal of Arts \& Humanities.

MaríaCubillo, J., Sánchez, J., \& Cerviño, J. (2006). International students' decision-making process. International Journal of Educational Management.https://doi.org/10.1108/09513540610646091

Martin, A. J., Nejad, H. G., Colmar, S., \& Liem, G. A. D. (2013). Adaptability: How students' responses to uncertainty and novelty predict their academic and non-academic outcomes. Journal of Educational Psychology.https://doi.org/10.1037/a0032794

McKenzie, K. \& Schweitzer, R. (2001). Who succeeds at university? Factors predicting academic performance in first year Australian university students. Higher Education Research and Development.https://doi.org/10.1080/07924360120043621

McKenzie K, Gow, K. \& Schweitzer, R (2004). Exploring first year academic achievement through structural 
equation modelling. Higher Education Research and Development.https://doi.org/10.1080/0729436032000168513

Ministry of Education of the People's Republic of China. (2017). National statistics for international students studying in China in 2016.

Mobasseri, S., Goldberg, A., \& Srivastava, S. B. (2017). What is Cultural Fit? From Cognition to Behavior (and Back).

Morley, L., Alexiadou, N., Garaz, S., González-Monteagudo, J., \& Taba, M. (2018). Internationalisation and migrant academics: the hidden narratives of mobility. Higher Education.https://doi.org/10.1007/s10734-017-0224-z

Morrison, J., Merrick, B., Higgs, S., \& Le Metais, J. (2005). Researching the performance of international students in the UK. Studies in Higher Education.https://doi.org/10.1080/03075070500095762

Nabil El-Hilali, Sara Al-Jaber \& Lina Hussein (2015). Students' Satisfaction and Achievement and Absorption Capacity in Higher Education. Procedia - Social and Behavioral Sciences.https://doi.org/10.1016/j.sbspro.2015.02.384

Nallaya, S. S. (2018). An exploration of how first year students are inducted into their discipline's academic discourses. International Journal of Educational Research.https://doi.org/10.1016/j.ijer.2017.11.007

Norton, A. (2016). Mapping Australian higher education 2016. Grattan Institute.

Ortlieb, R., \& Weiss, S. (2018). What makes academic careers less insecure? The role of individual-level antecedents. Higher Education.https://doi.org/10.1007/s10734-017-0226-x

Pampaka, M., Pepin, B., \&Sikko, S. A. (2016). Supporting or alienating students during their transition to Higher Education: Mathematically relevant trajectories in the contexts of England and Norway. International Journal of Educational Research.https://doi.org/10.1016/j.ijer.2016.06.008

Pervin, L. A. (1968). Performance and satisfaction as a function of individual-environment fit. Psychological Bulletin.https://doi.org/10.1037/h0025271

Posselt, J. R., Reyes, K. A., Slay, K., Kamimura, A., \& Porter, K. (2017). Equity efforts as boundary work: How symbolic and social boundaries shape access and inclusion in graduate education. Teachers College Record.

Posselt, J. (2018). Normalizing Struggle: Dimensions of Faculty Support for Doctoral Students and Implications for Persistence and Well-Being. The Journal Higher Education.https://doi.org/10.1080/00221546.2018.1449080

Powell, K. (2016). Does it take too long to publish research? Nature. Retrieved from http://www.nature.com/news/does-it-take-too-long-to-publish-research-1.19320

PoyatosMatas, C. (2012). Doctoral education and skills development: An international perspective. Revista de DocenciaUniversitaria.

Ploner, J. (2018). International students' transitions to UK Higher Education-revisiting the concept and practice of academic hospitality. Journal of Research in International Education.https://doi.org/10.1177/1475240918786690

Rienties, B., Beausaert, S., Grohnert, T., Niemantsverdriet, S., \& Kommers, P. (2012). Understanding academic performance of international students: the role of ethnicity, academic and social integration. Higher education.https://doi.org/10.1007/s10734-011-9468-1

Rhew, E., Piro, J. S., Goolkasian, P., \& Cosentino, P. (2018). The effects of a growth mindset on self-efficacy and motivation. Cogent Education.https://doi.org/10.1080/2331186X.2018.1492337

Salisbury, M. H. (2011). The effect of study abroad on intercultural competence among undergraduate college students (Doctoral dissertation). Retrieved fromProQuest Dissertations and Theses Database.

Smith, P. J. \& Smith S. N. (1999). Differences between Chinese and Australian students: some implications for distance educators. Distance Education.https://doi.org/10.1080/0158791990200106

Smith, S. (2015). Phd by published work: A practical guide for success. London: Palgrave.

Stevens, J.P. (1992). Applied Multivariate Statistics for the Social Sciences (2nd edition). Hillsdale, NJ: Erlbaum

Taylor, M. (2005). Catch 'em while you can, special report on The Guardian retrieved from: http://education.guardian.co.uk/students/tuitionfees/story/0,,1407667,00.html. 
Tabachnick, B. G., \& Fidell, L. S. (2007). Using multivariate statistics. Allyn \& Bacon/Pearson Education.

Terenzini, P. \& Pascarella, E. (1978). The relation of students' precollege characteristics and freshman year experience to voluntary attrition. Research in Higher Education.https://doi.org/10.1007/BF00991406

Ting, H. F., Wang, H. B., \& Wang, D. S. (2012). The moderating role of environmental dynamism on the influence of innovation strategy and firm performance. International Journal of Innovation, Management and Technology.https://doi.org/10.7763/IJIMT.2012.V3.288

Trudgett, M. (2014). Supervision provided to Indigenous Australian doctoral students: A black and white issue. Higher Education Research\& Development.https://doi.org/10.1080/07294360.2014.890576

Turki, F. J., Jdaitawi, M., \& Sheta, H. (2017). Fostering positive adjustment behaviour: Social connectedness, achievement motivation and emotional-social learning among male and female university students. Active Learning in Higher Education.https://doi.org/10.1177/1469787417731202

Wang, J., Wang, J., Yang, J., Yang, J., Xue, Y., \& Xue, Y. (2017). Subjective well-being, knowledge sharing and individual innovation behavior: The moderating role of absorptive capacity. Leadership \& Organization Development Journal.https://doi.org/10.1108/LODJ-10-2015-0235

Waters, C. W., Ambler, R., \& Waters, L. K. (1976). Novelty and sensation seeking in two academic training settings. Educational and psychological Measurement.https://doi.org/10.1177/001316447603600227

Webster F, Pepper D \& Jenkins A (2000). Assessing the undergraduate dissertation. Assessment and Evaluation in Higher Education.https://doi.org/10.1080/02602930050025042

Wen, W., Hu, D., \& Hao, J. (2018). International students' experiences in China: Does the planned reverse mobility work? International Journal of Educational Development.https://doi.org/10.1016/j.ijedudev.2017.03.004

Yee, P. L., Pierce, G. R., Ptacek, J. T. \& Modzelesky, K. L. (2004). Learner helplessness attributional style and examination performance: Enhancement effects are not necessarily moderated by prior failure. Anxiety, Stress, and Coping. https://doi.org/10.1080/0003379031000140928

Yorke, M. (1991). Performance Indicators: Observations on Their Use in the Assurance of Course Quality (CNAA Project Report 30), Council for National Academic Awards, London.

Young, W. S., Seong, W. C., \& Kun, C. L (2014). The impact of absorptive capacity, exploration, and exploitation on individual creativity: Moderating effect of subjective well-being.Computers in Human Behaviorhttps://doi.org/10.1016/j.chb.2014.03.031

Xiao-jiong, D. I. N. G. (2010). What Kind of Education Do International Students in China Need-On the Basis of Data from Four Universities in Shanghai. Journal of Higher Education.

Zhao, C. M., Kuh, G. D., \& Carini, R. M. (2005). A comparison of international student and American studentengagement in effective educational practices. The Journal of Higher Education.https://doi.org/10.1353/jhe.2005.0018

\section{Note}

Note 1 . For any information about the questionnaire, please write to the corresponding author. 